\title{
An Open-Label Study of Low-Level Laser Therapy Followed by Autologous Fibroblast Transplantation for Healing Grade 3 Burn Wounds in Diabetic Patients
}

\author{
Mohammad Ali Nilforoushzadeh', Nooshafarin Kazemikhoo ${ }^{2,3^{*}}$, Soheila Mokmeli ${ }^{4}$, Sona Zare ${ }^{1,5}$, Mostafa \\ Dahmardehei $^{6}$, Reza Vaghar Doost ${ }^{6}$, Mahnoush Momeni ${ }^{6}$, Fereshteh Ansari ${ }^{7,8}$ \\ ${ }^{1}$ Skin and Stem Cell Research Center,Tehran University of Medical Sciences, Tehran, Iran \\ ${ }^{2}$ Laser Application in Medical Sciences Research Center, Shahid Beheshti University of Medical Sciences, Tehran, Iran \\ ${ }^{3}$ Department of Dermatology, St. George Hospital, UNSW, Sydney, Australia \\ ${ }^{4}$ Canadian Optic and Laser Centre, COL Centre, BC, Canada \\ ${ }^{5}$ Department of Biology, Faculty of Science, Islamic Azad University, Hamedan Branch, Hamedan, Iran \\ ${ }^{6}$ Burn Research Centre, Department of Plastic and Reconstructive Surgery, Iran University of Medical Sciences, Tehran, Iran \\ ${ }^{7}$ Research Centre for Evidence-Based Medicine, Health Management and Safety Promotion Research Institute, Tabriz \\ University of Medical Sciences, Tabriz, Iran \\ ${ }^{8}$ Iranian EBM Centre: A Joanna Briggs Institute Affiliated Group
}

\section{*Correspondence to} Nooshafarin Kazemikhoo, Email: z3526505@unsw.edu.au nooshakazemi@gmail.com

Published online December 1, 2019

\begin{abstract}
Introduction: Low-level laser therapy (LLLT) has been used as an effective therapeutic modality since the mid-1960s. Although there have been several clinical studies using LLLT in wound healing, especially diabetic, pressure and venous ulcers, there are few reports of using this technique in burn ulcers. Autologous fibroblast transplantation is a novel treatment for patients with burns or venous ulcers. In this study for the first time, we used LLLT along with autologous fibroblast skin transplantation to treat grade 3 burn ulcers in diabetic patients. This case series describes the successful management of grade 3 burn ulcers in 10 diabetic patients using autologous fibroblast transplantation along with LLLT.

Methods: After the approval of the Tehran University Ethics Committee (IR.TUMS.REC.1394.1683) and the Iran Registry of Clinical Trials (IRCT2016050226069N3), 10 diabetic patients with 10 grade 3 burn ulcers, who were a candidate for skin graft surgery, entered the study. Donor skin was biopsied using a $3 \mathrm{~mm}$ punch. Fibroblasts were extracted and cultured in vitro in the GMP Technique laboratory. The patients were treated using LLLT in 3-4 weeks during the time that fibroblast cultures became ready to use. Laser irradiation was done using red light, $650 \mathrm{~nm}, 150$ $\mathrm{mW}, 1 \mathrm{~J} / \mathrm{cm}^{2}$ for the bed of the ulcer and infra-red light $808 \mathrm{~nm}, 200 \mathrm{~mW}, 6 \mathrm{~J} / \mathrm{cm}^{2}$ for the margins every other day for 10 sessions.

Results: The mean wound size before treatment was $16.28 \mathrm{~cm}^{2}$. All patients' burn wounds healed completely after 10-12 weeks.

Conclusion: We conclude that this method can be used as an effective method for treating large wounds, especially in complicated patients including the diabetics.

Keywords: Low-level laser therapy; Autologous fibroblast transplantation; Burn wound.
\end{abstract}

\section{Introduction}

Millions of patients are hospitalized due to burn ulcers and more than 300000 of them die of complications. ${ }^{1}$ The healing process in these patients is complicated due to poor blood supply and infection. ${ }^{2}$ Spontaneous healing of these ulcers may cause scar formation and the patients may need surgical treatments including auto or allograft which may have limitations because of antigenicity or insufficient donor skin. ${ }^{3}$

Several therapeutic modalities have been introduced for accelerating the closure time and decreasing scar formation of these ulcers, including different kinds of dressings, growth factors, and surgical methods. ${ }^{4,5}$ Autologous fibroblast or keratinocyte transplantation is one of the novel treatments for patients with burns or venous ulcers. ${ }^{6-8}$ Studies show that activated autologous fibroblasts can provide the fibroblast growth factor, the platelet-derived growth factor, and the vascular, endothelial growth factor and have a significant effect on extracellular matrix formation, differentiation, and 
epidermal proliferation. ${ }^{5,9}$ A major problem is that cultivating sufficient amounts of fibroblasts requires at least 3-4 weeks ${ }^{10}$ and burn areas need therapeutic supports during this time.

Low-level laser therapy (LLLT) has been used as an effective, safe, and non-invasive treatment for wound healing. Low-power lasers have no thermal effects and can accelerate the healing process by stimulating microcirculation, fibroblast proliferation, granulation tissue formation, collagen synthesis, and immune system modulation. Studies show that laser therapy improves cellular metabolic processes and the regenerative capacity of injured tissues. ${ }^{11-13}$

Our previous reports manifested the significant effects of using LLLT on the treatment of foot ulcers, burn ulcers, neuropathy, and the metabonomic of diabetic patients, ${ }^{14-18}$ increasing growth factors, ${ }^{19}$ the improvement of healing after cesarean surgery ${ }^{20}$ and coronary bypass grafting. ${ }^{21}$

In this study, we evaluated two modern therapies, LLLT for phase 1 (the first 3-4 weeks that fibroblast culture lasts) and autologous fibroblast transplantation as phase 2 in patients with grade 3 burn ulcers.

\section{Methods}

The diabetic patients (30-68 years old) with chronic grade 3 burn ulcers (according to the University of Texas wound classification system ${ }^{22}$ ) who were hospitalized in Shahid Motahari Burn center entered the study. They had received classic diabetic wound care including glycemic control, topical and oral antibiotic therapy for the infected wounds according to wound culture, offloading and surgical debridement, but they had no sign of improvement after 6 weeks. The patients' primary data are shown in Table 1 .

The exclusion criteria were pregnancy, photosensitivity, chronic disease that needed medication, and malignancy. After filling the questionnaire and the informed consent, standard photographs were taken of all patients using an iPhone 5 camera without flash. For obtaining fibroblast, a $3 \mathrm{~mm}$ punch was used for a skin biopsy from the retroauricular area after anesthesia with lidocaine $2 \%$. The skin biopsies were placed in sterile culture media (RPMI) with $100 \mathrm{U} / \mathrm{ML}$ penicillin + 100U/ML streptomycin (ATOCEL, Austria, ATRA-010) and were transferred to a clean room of the skin and stem cell research center for culturing using GMP techniques. For 3-4 weeks, LLLT was done using red light (Canadian Optic Laser Center, COL Laser, Canada), $650 \mathrm{~nm}, 150 \mathrm{~mW}, 1 \mathrm{~J} / \mathrm{cm}^{2}$ for the bed of the ulcer and infra-red light $808 \mathrm{~nm}, 200 \mathrm{~mW}, 6 \mathrm{~J} / \mathrm{cm}^{2}$ (Azor 2k Laser, Russia) for the margins every other day.

\section{Cell Culture}

The biopsied skins were washed with DMEM (ATOCEL, Austria ATCDH883) plus penicillin and streptomycin (ATOCEL, Austria, ATRA-010) three times, the fatty layers of the skins were removed, and the skins were cut into small pieces using a scalpel and were transferred into a $15 \mathrm{~mL}$ round-bottomed tube. $0.1 \%$ collagenase type 1 (ATOCEL, Austria) was added and incubated 2 hours at $37^{\circ} \mathrm{C}, \mathrm{Co} 25 \%$ and $95 \%$ humidity. After shaking and centrifuging at $1000 \mathrm{rpm}$ for 5 minutes, sediment was added to 6 well plates and $1 \mathrm{~mL}$ high glucose DMEM (ATOCEL, Austria, ATCDH883), supplemented with $10 \%$ bovine serum, was added to each well. The medium was changed to a fresh one every 2 days. Upon reaching $80 \%-90 \%$ confluency, the cells were detached using trypsin 0.25\% (ATOCEL, Austria, ATRE 10810) and sub-cultured in a $25 \mathrm{~cm}^{2}$ cell flask. The plates were microscopically verified to guarantee that the cells were confluent and there was no contamination. The cultured cells were tested for mycoplasma, fungi and bacterial contamination. After 3-4 weeks, 20 million fibroblasts were isolated and suspended in $1 \mathrm{~mL}$ phosphate-buffered saline (PBS) for transplantation.

\section{Transferring Cells to the Wound Area}

We used trichloroacetic acid (TCA) 50\% for chemical debridement of hyperkeratotic surrounding tissue. ${ }^{23}$ Then the bases of ulcers were abraded by a surgical scalpel No. 15 to create pinpoint bleeding. After washing the wound surface with normal saline, a thin layer of fibroblast suspension was applied to the base of the ulcer using a sterile sampler and its surface was covered by Vaseline gauze and a Mepitel (Molnlycke health care, Sweden) dressing and a Tegaderm (3M, America) dressing over the Vaseline gauze to fix the cells. The Tegaderm dressing has a thin polyurethane membrane coated with acrylic adhesive. To prevent secondary infection, cephalexin 500 mg was prescribed four times a day for seven days. The dressing was removed on day seven. The patients were evaluated every other day until complete closure of the
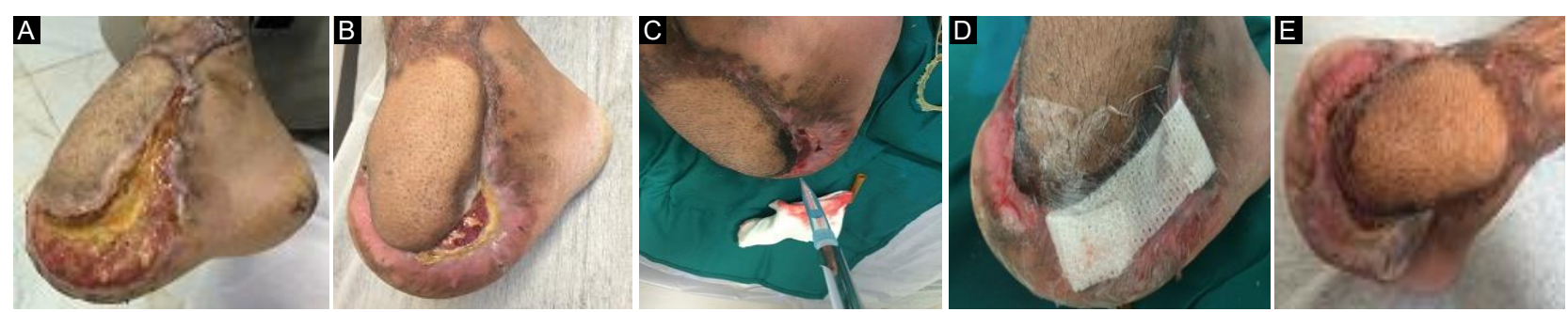

Figure 1. (A) The burn ulcer in diabetic patients with previous amputation surgery. B: After 10 sessions of LLLT. C: Treating the ulcer with autologous fibroblast suspension. (D) The Tegaderm dressing. (E) Treatment completion. 
wound. Photography was done at the end of the treatment and the pictures were analyzed using PictZar software (Figure 1). Statistical analysis was carried out using IBM SPSS version 21.

\section{Results}

Ten patients were recruited for this study. Of these patients, $7(70 \%)$ were male and $3(30 \%)$ were female. The mean age of them was 47 (SD: 12.96) years (range: 30 to 68 years). The mean size of burn ulcers was 16.28 $\mathrm{cm}^{2}$ (SD: $8.94 \mathrm{~cm}^{2}$ ). The minimum size of these ulcers was $8.20 \mathrm{~cm}^{2}$ and the maximum size of them was 31.03 $\mathrm{cm}^{2}$. Of these ten ulcers, $2(20 \%)$ healed completely after 10 weeks, 5 (50\%) remained after 11 weeks and $3(30 \%)$ lasted after 12 weeks from the treatment onset.

There was no linear correlation between the time to complete healing and the age of the patients (Pearson's $r=0.511, P=0.131)$ nor was there between the time to complete healing and the initial size of burn ulcers (Pearson's $\mathrm{r}=0.476, P=0.165$ ).

\section{Discussion}

In this case series for the first time, we report the effect of autologous fibroblast skin transplantation along with low-level laser irradiation in treating grade 3 burn ulcers in diabetic patients, candidates for split-thickness skin graft surgery. Complete healing occurred in all patients in at least 3 months. Our previous study showed that using LLLT after a skin graft is an effective therapeutic modality. ${ }^{14,24,25}$ Although the autologous skin graft is the gold standard for covering skin defects in deep burn ulcers, this method has several complications including the need to hospitalization, the risk of anesthesia and surgery, especially in patients with cardiovascular diseases, the limitation of the donor site in extensive burns, graft failure, especially in diabetic patients and donor site scars. ${ }^{26}$ In this study, instead of harvesting a larger area of skin as the donor site for grafting on the damaged area, we just biopsied $3 \mathrm{~mm}$ of the patients' post-auricular area and culture fibroblast, along with LLLT. Our results showed complete healing in all patients in at least 3 months. Although this process is longer than using LLLT along with skin graft surgery which lasts at least 2 months, ${ }^{13}$ it had several advantages, including treating outpatient without need to hospitalization, avoiding surgery and its risks and independence of harvesting skin for the donor site which sometimes forms hypertrophic scars.

In our previous study, we irradiated an infra-red 810 $\mathrm{nm}$ laser on cultured skin fibroblasts of diabetic and nondiabetic mice. Our results showed that laser irradiation significantly increased the fibroblast growth factor gene expression in the diabetic mice. Although laser irradiation also increased the expression of the platelet-derived growth factor, it was not statistically significant. ${ }^{19}$

Cell therapy has been applied in treating burn ulcers since $1975 .{ }^{27}$ Dermal replacement with fibroblast culture

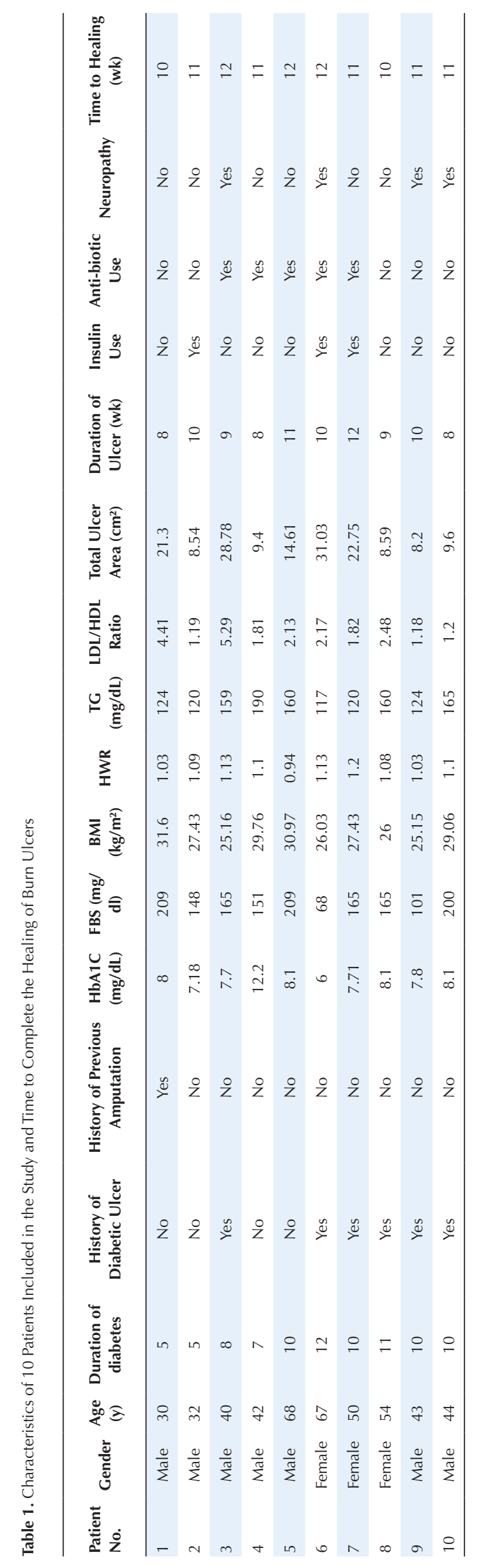


can provide an extracellular matrix, vascularization, and granulation tissue formation and it can support the epithelial layer. ${ }^{28}$ Braye et al used a widely meshed autograft with autologous cultured epithelium for treating an extensive burn in children. ${ }^{29}$ Wisser and Steffes reported the successful use of autologous keratinocyte and fibroblast in a burned patient. ${ }^{6}$ Owen et al reported the successful use of a tissue-engineered dermal graft containing neonatal skin fibroblast for the treatment of ulcerated necrobiosis lipoidica. ${ }^{30}$ Nilforoushzadeh et al reported treating a burn ulcer in diabetic patients, using autologous fibroblast suspension. ${ }^{23}$ They also used this technique for soft tissue augmentation and the treatment of scars and wrinkles. ${ }^{31}$

Several meta-analyses and reviews suggest LLLT as an effective therapeutic modality for wound healing. ${ }^{32-34}$ Most of these clinical studies are on diabetic, venous and pressure ulcers $^{32,33,35}$ and the effect of laser therapy on burn ulcers is studied only on animal models. ${ }^{36}$ Mester, the pioneer of using LLLT in wound healing, studied the effect of laser therapy on burn ulcers in mice. He concluded that laser irradiation stimulates the healing process by increasing epithelial formation. ${ }^{37}$

Dantas et al used sodium alginate/chitosan-based films along with LLLT for treating burn ulcers in mice. They reported that the combination of these two methods improves healing by modulating epithelialization, collagen formation and neovascularization..$^{38}$ Bayat et al reported that using laser therapy on deep second-degree burns in rats decreased the incidence of infection with Staphylococcus aureus and epidermis. ${ }^{39}$ Ezzati et al showed that LLLT promoted the healing of third-degree burn ulcers in rats. ${ }^{40}$

The only clinical report was our previous study on the effect of LLLT on a type 3 burn ulcer in diabetic patients after a skin graft. We concluded that LLLT is an effective therapeutic modality in burn ulcers. ${ }^{14}$ Gaida et al reported that LLLT had positive effects on patients with burn scars. ${ }^{41}$

Almeida-Lopes et al studied the effect of LLLT on the proliferation of cultured human gingival fibroblasts. They concluded that laser therapy improved the proliferation of fibroblasts in vitro. ${ }^{12}$

\section{Conclusion}

A delay in burn wound healing increases patients' pain and discomfort, the rate of infection, the likelihood of surgical procedures and the duration of hospitalization. Applying autologous fibroblast skin culture along with LLLT may decrease these morbidities and can be used as an effective therapeutic modality in patients with high risks for surgery or those who do not agree with skin graft surgery.

\section{Ethical Considerations}

The protocols and the informed consent were reviewed in the Medical Ethics Board of Tehran University of Medical Sciences (IR.TUMS.REC.1394.1683) and Iran Registry of Clinical trials (identifier: IRCT2016050226069N3; http:// en.irct.ir/trial/21708).

\section{Conflict of Interests}

The authors declare no conflict of interest.

\section{Acknowledgement}

We appreciate the Canadian Laser and Optics Co. Ltd and Behsaz Laser instruments Co. Ltd for their instrumental supports and the Skin and Stem Cell Research Centre for financial support. We would also like to acknowledge Motahari Burn Center staff and our patients for their ongoing involvement.

\section{References}

1. Ghanassia E, Villon L, dit Dieudonné J-FT, Boegner C, Avignon A, Sultan A. Long-term outcome and disability of diabetic patients hospitalized for diabetic foot ulcers a 6.5-year follow-up study. Diabetes Care. 2008;31(7):128892. doi: $10.2337 / \mathrm{dc} 07-2145$

2. Lavery LA, Armstrong DG, Wunderlich RP, Mohler MJ, Wendel CS, Lipsky BA. Risk factors for foot infections in individuals with diabetes. Diabetes Care. 2006;29(6):128893. doi: $10.2337 / \mathrm{dc} 05-2425$

3. Shakespeare P. Burn wound healing and skin substitutes. Burns. 2001;27(5):517-22. doi: 10.1016/S03054179(01)00017-1

4. Taheri A, Mansoori P, Al-Dabagh A, Feldman SR. Are corticosteroids effective for the prevention of scar formation after second-degree skin burn? J Dermatol Treat. 2014;25(4):360-2. doi: 10.3109/09546634.2013.806768

5. Wong $\mathrm{T}, \mathrm{McGrath} J$, Navsaria $\mathrm{H}$. The role of fibroblasts in tissue engineering and regeneration. $\mathrm{Br}$ J Dermatol. 2007;156(6):1149-55. doi: 10.1111/j.13652133.2007.07914.x

6. Wisser D, Steffes J. Skin replacement with a collagen based dermal substitute, autologous keratinocytes and fibroblasts in burn trauma. Burns. 2003;29(4):375-80. doi: 10.1016/ S0305-4179(03)00013-5

7. Fimiani M, Pianigiani E, Di Simplicio FC, Sbano P, Cuccia A, Pompella G, et al. Other uses of homologous skin grafts and skin bank bioproducts. Clinic Dermatol. 2005;23(4):396402. doi: 10.1016/j.clindermatol.2004.07.025

8. Zare S, Anjomshoa M, Kurd S, Chai J-K, Dahmardei M, Nilforoushzadeh MA, et al. Regenerative medicine: novel approach in burn wound healing. J Skin Stem Cell. 2015;2(2):e30351. doi: 10.17795/jssc30351

9. Jaffary F, Changizi V, Mardani H, Kakanezhadian P, Javadi FM, Nilforoushzadeh MA, et al. Macroscopic effect of blue light cure on wound healing in NMRI mice NMRI. $A d v$ Biomed Res. 2014;3(1):106. doi: 10.4103/2277-9175.129699

10. Llanos S, Danilla S, Barraza C, Armijo E, Piñeros JL, Quintas $M$, et al. Effectiveness of negative pressure closure in the integration of split thickness skin grafts: a randomized, double-masked, controlled trial. Ann Surg. 2006;244(5):700-5. doi: 10.1097/01. sla.0000217745.56657.e5 
11. Bihari I, Mester AR. The biostimulative effect of lowlevel laser therapy of long-standing crural ulcers using helium-neon laser, helium-neon plus infrared lasers, and noncoherent light: preliminary report of a randomized double blind comparative study. Laser Ther. 1989;1(2):978.

12. Almeida-Lopes L, Rigau J, Zângaro RA, Guidugli-Neto J, Jaeger MM. Comparison of the low level laser therapy effects on cultured human gingival fibroblasts proliferation using different irradiance and same fluence. Lasers Surg Med. 2001;29(2):179-84. doi: 10.1002/lsm.1107

13. Moravvaej H, Daneshvar L, Saeedi M, Barzegar MR. Treatment of a pigmented hypertrophic scar by low-level laser therapy (LLLT): a case report. J Lasers Med Sci. 2010;1(1):35-8. doi: 10.22037/jlms.vli1.2135

14. Dahmardehei M, Kazemikhoo N, Vaghardoost R, Mokmeli S, Momeni M, Nilforoushzadeh MA, et al. Effects of low level laser therapy on the prognosis of split-thickness skin graft in type 3 burn of diabetic patients: a case series. Lasers Med Sci. 2016;31(3):497-502. doi: 10.1007/s10103016-1896-9

15. Kazemi-Khoo N. Successful treatment of diabetic foot ulcers with low-level laser therapy. Foot. 2006;16(4):184-7. doi: 10.1016/j.foot.2006.05.004

16. KazemiKhoo N, Ansari F. Blue or red: which intravascular laser light has more effects in diabetic patients? Lasers Med Sci. 2015;30(1):363-6. doi: 10.1007/s10103-014-1672-7

17. Khamseh ME, Kazemikho N, Aghili R, Forough B, Lajevardi M, Dabaghian FH, et al. Diabetic distal symmetric polyneuropathy: effect of low-intensity laser therapy. Lasers Med Sci. 2011;26(6):831-5. doi: 10.1007/ s10103-011-0977-z

18. Kazemi Khoo N, Iravani A, Arjmand M, Vahabi F, Lajevardi M, Akrami SM, et al. A metabolomic study on the effect of intravascular laser blood irradiation on type 2 diabetic patients. Lasers Medl Sci. 2013;28(6):1527-32. doi: 10.1007/s10103-012-1247-4

19. Khoo NK, Shokrgozar MA, Kashani IR, Amanzadeh A, Mostafavi E, Sanati H, et al. In vitro therapeutic effects of a low-level laser at mRNA level on the release of skin growth factors from fibroblasts in diabetic mice. Avicenna J Med Biotechnol. 2014;6(2):113-8.

20. Mokmeli S, Khazemikho N, Niromanesh S, Vatankhah Z. The application of low-level laser therapy after cesarean section does not compromise blood prolactin levels and lactation status. Photomed Laser Surg. 2009;27(3):509-12. doi: 10.1089/pho.2008.2314

21. Kazemi Khoo N, Babazadeh K, Lajevardi M, Dabaghian FH, Mostafavi E. Application of low-level laser therapy following coronary artery bypass grafting (CABG) surgery. J Lasers Med Sci. 2014;5(2):86-91. doi: 10.22037/jlms. v5i2.4564

22. Lavery LA, Armstrong DG, Harkless LB. Classification of diabetic foot wounds. Foot Ankle Surg. 1996;35(6):528-31. doi: 10.1016/S1067-2516(96)80125-6

23. Nilforoushzadeh MA, Jaffary F, Siavash M, Ansari N, Siadat AH, Heidari A. Autologous fibroblast suspension for the treatment of refractory diabetic foot ulcer. Indian J Dermatol Venereol Leprol. 2016;82(1):105-6. doi: 10.4103/0378-6323.172905
24. Vaghardoost R, Momeni M, Kazemikhoo N, Mokmeli S, Dahmardehei M, Ansari F, et al. Effect of low-level laser therapy on the healing process of donor site in patients with grade 3 burn ulcer after skin graft surgery (a randomized clinical trial). Lasers Med Sci. 2018;33(3):6037. doi: 10.1007/s10103-017-2430-4

25. Kazemikhoo N, Vaghardoost R, Dahmardehei M, Mokmeli S, Momeni M, Nilforoushzadeh MA, et al. Evaluation of the effects of low level laser therapy on the healing process after skin graft surgery in burned patients (a randomized clinical trial). J Lasers Med Sci. 2018;9(2):139-43. doi: $10.15171 / \mathrm{jlms} .2018 .26$

26. Isitt CE, McCloskey KA, Caballo A, Sharma P, Williams A, Leon-Villapalos J, et al. An analysis of surgical and anaesthetic factors affecting skin graft viability in patients admitted to a Burns Intensive Care Unit. Scars Burn Heal. 2016;2: 1-11. doi: 10.1177/2059513116642089

27. Leclerc T, Thepenier C, Jault P, Bey E, Peltzer J, Trouillas M, et al. Cell therapy of burns. Cell Prolif. 2011;44(1):4854. doi: 10.1111/j.1365-2184.2010.00727.x

28. Burke JF, Yannas IV, Quinby WC Jr, Bondoc CC, Jung WK. Successful use of a physiologically acceptable artificial skin in the treatment of extensive burn injury. Ann Surg. 1981;194(4):413-28. doi: 10.1097/00000658-19811000000005

29. Braye F, Oddou L, Bertin-Maghit M, Belgacem S, Damour $\mathrm{O}$, Spitalier $\mathrm{P}$, et al. Widely meshed autograft associated with cultured autologous epithelium for the treatment of major burns in children: report of 12 cases. Eur J Pediatr Surg. 2000;10(1):35-40. doi: 10.1055/s-2008-1072320

30. Owen C, Murphy H, Yates VM. Tissue-engineered dermal skin grafting in the treatment of ulcerated necrobiosis lipoidica. Clin Exp Dermatol. 2001;26(2):176-8. doi: 10.1046/j.1365-2230.2001.00789.x

31. Nilforoushzadeh MA, Siadat AH, Arianrad M, Moulavi F, Baradaran EH, Esfahani MHN. Soft tissue augmentation by autologous cultured fibroblasts transplantation for treatment of wrinkles and scars: a case series of 20 patients. J Res Med Sci:2010;15(3):167-71.

32. Woodruff LD, Bounkeo JM, Brannon WM, Dawes KS, Barham CD, Waddell DL, et al. The efficacy of laser therapy in wound repair: a meta-analysis of the literature. Photomed Laser Surg. 2004;22(3):241-7. doi: 10.1089/1549541041438623

33. Schindl A, Schindl M, Pernerstorfer-Schön H, Schindl L. Low-intensity laser therapy: a review. J Investig Med. 2000;48(5):312-26.

34. Beckerman $\mathrm{H}$, de Bie RA, Bouter LM, De Cuyper HJ, Oostendorp RA. The efficacy of laser therapy for musculoskeletal and skin disorders: a criteria-based meta-analysis of randomized clinical trials. Phys Ther. 1992;72(7):483-91. doi: 10.1093/ptj/72.7.483

35. Lucas C, van Gemert MJ, de Haan R. Efficacy of low-level laser therapy in the management of stage III decubitus ulcers: a prospective, observer-blinded multicentre randomised clinical trial. Lasers Med Sci . 2003;18(2):72-7. doi: 10.1007/s10103-003-0259-5

36. Cambier DC, Vanderstraeten GG, Mussen MJ, van der Spank JT. Low-power laser and healing of burns: a preliminary assay. Plast Reconstr Surg. 1996;97(3):555-8. 
doi: 10.1097/00006534-199603000-00009

37. Mester E, Spiry T, Szende B, Tota JG. Effect of laser rays on wound healing. Am J Surg. 1971;122(4):532-5. doi: 10.1016/0002-9610(71)90482-X

38. Dantas MD, Cavalcante DR, Araújo FE, Barretto SR, Aciole GT, Pinheiro AL, et al. Improvement of dermal burn healing by combining sodium alginate/chitosan-based films and low level laser therapy. J Photochem Photobiol B. 2011;105(1):51-9. doi: 10.1016/j.jphotobiol.2011.06.009

39. Bayat M, Vasheghani MM, Razavi N, Taheri S, Rakhshan M. Effect of low-level laser therapy on the healing of second- degree burns in rats: a histological and microbiological study. J Photochem Photobiol B. 2005;78(2):171-7. doi: 10.1016/j.jphotobiol.2004.08.012

40. Ezzati A, Bayat M, Taheri S, Mohsenifar Z. Low-level laser therapy with pulsed infrared laser accelerates thirddegree burn healing process in rats. $J$ Rehabil Res Dev. 2009;46(4):543-54. doi: 10.1682/JRRD.2008.09.0121

41. Gaida K, Koller R, Isler C, Aytekin O, Al-Awami M, Meissl $\mathrm{G}$, et al. Low Level Laser Therapy-a conservative approach to the burn scar? Burns. 2004;30(4):362-7. doi: 10.1016/j. burns.2003.12.012 